\title{
A COMBUSTÃO DA BIOMASSA E SEUS EFEITOS NA SAÚDE HUMANA EM ÁREAS URBANAS
}

\author{
Natacha Cíntia Regina Aleixo ${ }^{20}$ \\ João Lima Sant' Anna Neto ${ }^{21}$
}

\begin{abstract}
RESUMO
Os elementos climáticos como temperatura, umidade e precipitação inseridas no diagnóstico do clima urbano indica e as situações adversas que pessoas com uma predisposição de desenvolver e agravar uma patologia respiratória estão sujeitas. As condições atmosféricas vinculadas a certos níveis de poluição difundida no espaço urbano aumentam a área de risco de ocorrência das doenças respiratórias. Estas associações incluem variáveis como as condições socioeconômicas dos indivíduos expostos, os mecanismos de difusão dos poluentes na emissão e as principais áreas afetadas. A fonte de emissão de particulados e produtos gasosos na cidade de Ourinhos-SP ocorre no período da safra da agricultura canavieira pela combustão da cana-de-açúcar realizada dos meses de abril a dezembro constituindo graves impactos ambientais, contribuindo para a piora da qualidade do ar no ambiente intra-urbano e no aumento da morbidade por doenças respiratórias. Assim, o objetivo desta pesquisa é analisar o ritmo climático vinculado ao período da queima da canade-açúcar sobre a ocorrência de doenças respiratórias no espaço urbano de Ourinhos.
\end{abstract}

Palavras-chaves: clima, saúde, poluição atmosférica, doenças respiratórias.

\begin{abstract}
Climatic factors like temperature, humidity and rainfall linked in the urban climate diagnosis may indicate adverse situations that people with a predisposition to develop and aggravate respiratory condition are subject. Weather conditions linked to certain levels of pollution inserted in urban areas increase the risk of occurrence of respiratory diseases. These associations include some variables like socioeconomic conditions of individuals exposed, diffusion mechanisms of pollutants in the issue and main affected areas. The source of particulate emission of gaseous products in the Ourinhos-SP occurs during the harvest of sugar cane due to burning of crop made from April to

20 Mestranda em Geografia da Universidade Estadual Paulista - UNESP/Presidente Prudente. natachaaleixo@yahoo.com.br

${ }^{21}$ Dr. em Geografia e Professor Titular do Depto de Geografia da Universidade Estadual Paulista UNESP/Presidente Prudente. joaolima@fct.unesp.br
\end{abstract}


December. This action causes serious environmental impacts, contributing to decrease of quality of air in intra-urban environment and increase respiratory diseases morbidity. The objective of this research is to analyze the entailed climatic rhythm to the period of the burning of the sugar cane-of-sugar on the occurrence of respiratory illnesses in the urban space of Ourinhos.

Key-words: climate, health, air pollution, respiratory diseases.

\section{INTRODUÇÃO}

A fisiologia humana é extremamente vulnerável aos episódios climáticos extremos uma vez que, a variabilidade do clima, implica tanto em transformações ambientais nas paisagens naturais, quanto na qualidade de vida da população.

A alternância de períodos secos e chuvosos, principalmente no espaço urbano, pode estar na origem de desequilíbrios na relação entre atmosfera e superfície terrestre, influindo na dinâmica ambiental, e atingindo a população mais vulnerável aos efeitos agudos na saúde.

Nos últimos anos, as doenças do aparelho respiratório representaram a segunda maior causa de morbidade entre a população brasileira. Os dados do Estado de São Paulo demonstram similaridade com os dados nacionais. No ano de 2004, as estatísticas evidenciaram que a morbidade por doenças respiratórias avançou para o segundo lugar (12\%) na classificação do capítulo que trata da estatística internacional de doenças e problemas relacionados à saúde do CID $10^{22}$ perdendo para as internações por gravidez, parto e puerpério $(21,6 \%)$. Posteriormente às internações por doenças respiratórias, em terceiro lugar, com 11,7\%, encontra-se a morbidade por doenças do aparelho circulatório, que também sofre influência dos diferentes tempos atmosféricos pelas mudanças bruscas de pressão e temperatura.

Portanto, torna-se intrínseca a relação entre o ambiente geográfico na manifestação e a distribuição espacial de determinadas doenças. Alguns indicadores de saúde comprovam a fluente ocorrência de morbidade respiratória no Brasil, como se pode observar na Tabela 1, que demonstra que cerca de um quarto das internações realizadas no Sistema Único de Saúde (SUS), refere-se a atendimento ao parto, gravidez e puerpério. Excluindo-se esse grupo de internações, as doenças do aparelho respiratório aparecem como a segunda principal causa de morbidade hospitalar em todas as regiões, com pouco mais de $16 \%$ das internações.

A Organização Mundial da Saúde (OMS) estima que em 1995, morreram 4,3 milhões de crianças com idade inferior a cinco anos por doenças respiratórias agudas nos países em desenvolvimento, principalmente causadas por pneumonias. Umidade relativa do ar abaixo de $20 \%$ é considerada pela

\footnotetext{
${ }^{22} \mathrm{Na}$ classificação estatística internacional de doenças e problemas relacionados à saúde (CID 10), há um capítulo destinado especificadamente as doenças do aparelho respiratório. Fazem parte deste grupo de doenças às infecções agudas das vias aéreas superiores, como a influenza (gripe) e a pneumonia, as infecções agudas das vias aéreas inferiores, bem como as doenças crônicas tanto das vias aéreas superiores quanto inferiores. Também faz parte deste grupo, as doenças pulmonares devido a agentes externos, as afecções cancerígenas e supurativas das vias aéreas inferiores, as doenças de pleura e outras doenças do aparelho respiratório.
}

72

Setembro - 2009 
OMS, como de alto risco para a saúde, pois com a umidade relativa baixa e o aumento do número de poluentes lançados no ar há o agravamento e uma prédisposição das pessoas em contrair uma patologia respiratória.

Tabela 1. Internações hospitalares por grupos de causas no Brasil.

\begin{tabular}{|c|c|c|c|c|c|c|}
\hline \multicolumn{7}{|c|}{$\begin{array}{c}\text { Proporção }(\%) \text { de internações hospitalares SUS por grupos de causas } \\
\text { Brasil e grandes regióes } 1996 \text { a } 2000\end{array}$} \\
\hline \multirow{2}{*}{ Grupos de causas } & Brasil & Uorte. & Uordeste. & Sudeste. & Sill & Gentro Oeste \\
\hline & 19962000 & 19962000 & 19962000 & 19962000 & 19962000 & 19962000 \\
\hline $\begin{array}{c}\text { Doencas infecciosas } \\
\text { e parasitarias }\end{array}$ & $8,3-7,4$ & $14,4-13,5$ & $10,8-9,9$ & $5,8-5,1$ & $7,4-5,9$ & $7,5-6,6$ \\
\hline Neoplasias & $3,0-3,3$ & $1,9-2,1$ & $2,6-2,7$ & $3,6-3,8$ & $3,3-3,8$ & $2,1-2,6$ \\
\hline $\begin{array}{c}\text { Transtornos mentais } \\
\text { e compotamentais }\end{array}$ & $3,5-3,5$ & $0,7-0,6$ & $2,5-2,5$ & $5,1-5,0$ & $3,0-3,5$ & $2,8-3,4$ \\
\hline $\begin{array}{c}\text { Doenças do aparelho } \\
\text { circulatónio }\end{array}$ & $9,7-9,5$ & $5,0-5,1$ & $7,2-7,1$ & $11,5-11,3$ & $11,8-11,4$ & $10,5-10,2$ \\
\hline $\begin{array}{l}\text { Doenças do aparelho } \\
\text { respiratório }\end{array}$ & $16,9-16,2$ & $15,1-14,3$ & $17,3-17,9$ & $14,3-13,3$ & $22,2-19,8$ & $19,5-18,6$ \\
\hline $\begin{array}{c}\text { Doenças do aparelho } \\
\text { digestivo }\end{array}$ & $7,1-8,5$ & $7,0-8,5$ & $6,9-7,8$ & $7,2-8,4$ & $7,5-9,5$ & $7,1-9,7$ \\
\hline $\begin{array}{c}\text { Doenças do apare tho } \\
\text { geniturinário }\end{array}$ & $7,0-7,0$ & $9,0-8,5$ & $8,5-7,9$ & $6,0-6,3$ & $5,8-6,2$ & $6,5-7,3$ \\
\hline $\begin{array}{c}\text { Gravidez parto e } \\
\text { puerpério }\end{array}$ & $26,3-24,4$ & $31,1-29,5$ & $28,9-27,6$ & $25,0-23,7$ & $21,7-19,0$ & $27,1-22,3$ \\
\hline Causas externas & $6,2-5,8$ & $6,7-6,7$ & $4,8-4,7$ & $7,2-6,7$ & $5,9-5,5$ & $6,2-5,7$ \\
\hline Demais causas ** & $12,1-14,3$ & $9,0-11,2$ & $10,5-11,9$ & $14,4-16,4$ & $11,5-15,6$ & $10,8-13,5$ \\
\hline Total & 100.0 & 100.0 & 100.0 & 100.0 & 100.0 & 100.0 \\
\hline $\begin{array}{l}\text { *Segundo local d } \\
\text { onte: Mininstério da se }\end{array}$ & $\begin{array}{l}\text { idencia } \\
\text { SAS, SIH }\end{array}$ & Inclusive & ndeterm & & & \\
\hline
\end{tabular}

Inúmeras causas podem ocasionar o aumento no número de poluentes na atmosfera. Anualmente centenas de milhões de pessoas residentes nas metrópoles e cidades médias sofrem com a queima de combustível fóssil, se este fato é comprovado nestas áreas devido ao intenso tráfego de veículos, supõe-se também, que o aumento dos poluentes se dê por outras causas como a queima de cana-de-açúcar nas cidades médias e pequenas onde ocorre o predomínio das atividades agrícolas vinculada à própria economia local.

Por questões técnicas agrícolas, o período de queima da cana-de-açúcar no estado de São Paulo coincide com a época de estiagem. As queimadas lançam no ar, diversos poluentes, muitos deles tóxicos e cancerígenos que pelas correntes de vento, em grande parte dos episódios, atingem as áreas urbanas.

Portanto, a relação clima e saúde em função das condições atmosféricas, podem auxiliar na prevenção ou redução na ocorrência de doenças (pneumonia, bronquite, asma, insuficiência respiratória, fibrotorax, laringotraqueite, etc) uma vez que a poluição é um dos agravantes destas patogêneses.

Reconhecendo a crescente importância dos elementos climáticos para o bem estar humano, este artigo pretende analisar o ritmo climático vinculado ao período da queima da cana-de-açúcar sobre a ocorrência de doenças respiratórias no espaço urbano de Ourinhos. 
Neste contexto, escolheu-se como recorte espacial à cidade de Ourinhos, cuja agricultura de alta rentabilidade da monocultura canavieira influencia diretamente nas bases econômicas de todos os municípios limítrofes.

O município de Ourinhos localiza-se na região sudoeste do estado de São Paulo, com uma população de 99.071 habitantes (IBGE, 2001). Encontra-se a 493 metros acima do nível do mar, nas coordenadas de $22^{\circ} 58^{\circ} 28^{\prime \prime}$ de latitude sul, e $49^{\circ}$ 52'19" de longitude oeste (Figura 1). Apresenta topografia mais ou menos regular, levemente acidentada, e a hidrografia do sítio urbano conta com os rios Paranapanema, Pardo e Turvo (todos os três praticamente inseridos do perímetro urbano).

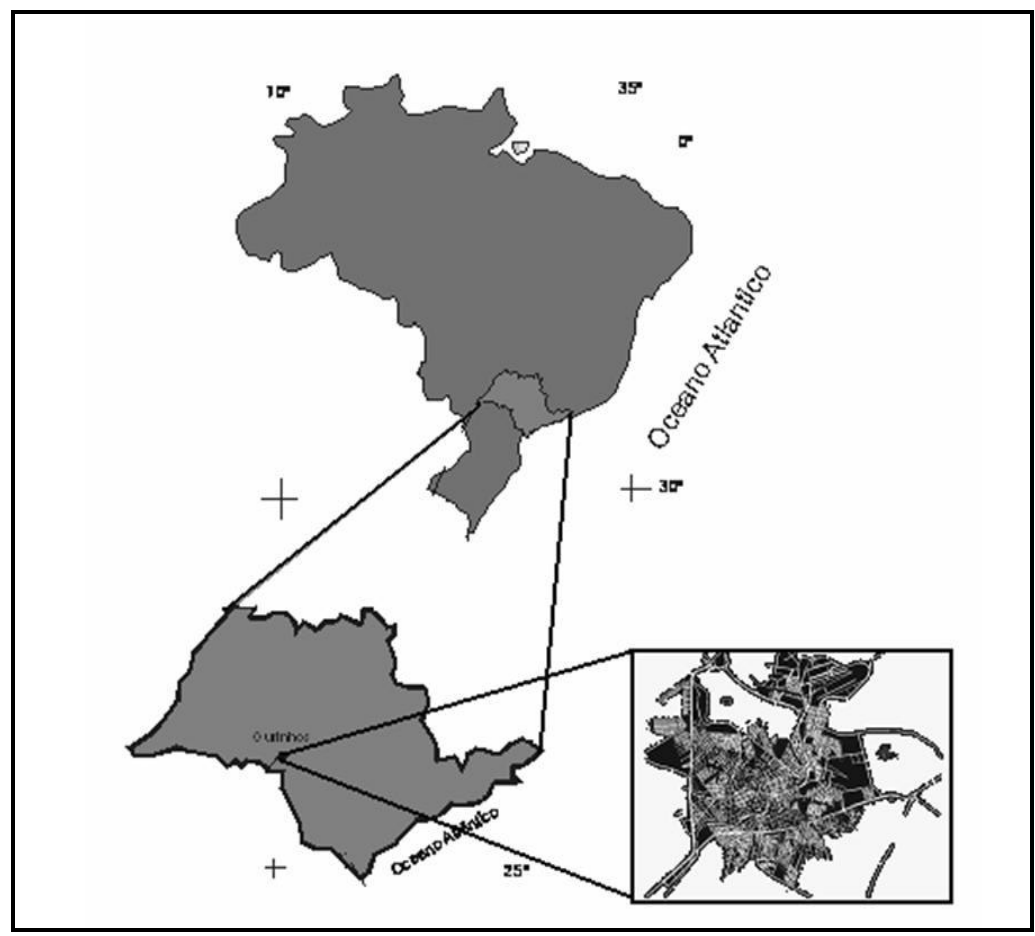

Figura 1. Localização da cidade de Ourinhos/SP.

Organização. ALEIXO (2006).

Encontra-se numa área de transição zonal entre os climas tropicais (controlados pelos sistemas equatoriais e tropicais), e subtropicais (pelos sistemas tropicais e polares), com maior influência de massas polares, no inverno e, oscilações no ritmo de temperaturas com a invasão de massas frias de trajetória continental, ocasionando ondas mais rigorosas de aquecimento pré-frontal. Sant'Anna Neto (2000), afirma que apesar das baixas altitudes (300 a $500 \mathrm{~m}$ ), a sub-região do Médio Vale do Rio Paranapanema recebe pluviosidade média anual de 1.300 a 1.600 mm, e que cerca de $73 \%$ desta precipitação está geneticamente associada

\section{PROCEDIMENTOS METODOLÓGICOS}

A metodologia utilizada nesta pesquisa baseou-se na análise do clima urbano proposta por Monteiro (1976) e no paradigma do ritmo climático, ou 
seja, a sucessão habitual dos tipos de tempo em uma análise episódica das variáveis: clima, poluição do ar e doenças respiratórias na abordagem do subsistema físico-químico do sistema clima urbano.

Foram utilizadas técnicas estatísticas clássicas na tabulação e tratamento dos dados termo-pluviométricos e higrícos. Os dados de qualidade do ar com as variáveis $\mathrm{CO}$ e Material Particulado 2,5, foram disponibilizados pelo modelo CATT/BRAMS do CPTEC/INPE, e analisados no software GRADS. O modelo CATT/BRAMS é baseado no acoplamento do modelo de transporte ao modelo RAMS - Regional Atmosferic Modeling System, os principais processos de transporte e remoção de traçadores na escala sub-grade são parametrizados e a simulação do transporte é realizada simultaneamente com a evolução do estado atmosférico.

Segundo Freitas et al (2007), para estas emissões serem bem representadas no modelo CATT-BRAMS, elas são calculadas diariamente pelo modelo 3BEM - Brazilian Biomass Burning Emission Model, CPTEC, (Freitas et al, 2005 e Longo et al 2006a) com base nos focos de calor identificados por sensoriamento remoto.

Os dados de inalações e internações por doenças respiratórias foram coletados na Unimed Ourinhos e DATASUS visando à correlação com o ambiente climático e a detecção das Unidades Básicas de Saúde da cidade com amplo atendimento em inalações.

Também, realizou-se um total de 400 entrevistas, com moradores nos bairros de abrangência das Unidades Básicas de Saúde, no intuito de compreender a principal época em que ocorrem os sintomas, a freqüência de utilização do serviço público de saúde, as principais fontes poluidoras e problemas socioambientais dos bairros.

\section{A queima da cana-de-açúcar no estado de São Paulo}

O Brasil é o maior produtor do mundo em cana-de-açúcar, com 4,5 bilhões de hectares do território nacional utilizados para o plantio, representando $1 \%$ das terras agricultáveis, ou mesmo, duas vezes o estado do Piauí. Este ramo da agricultura é responsável por $6 \%$ do PIB brasileiro, conforme é apresentado na Figura 5. Da safra canavieira $55 \%$ são destinados a produção do álcool e subprodutos e $45 \%$ a produção de açúcar e subprodutos, segundo a União da Agroindústria Canavieira (ÚNICA, 2007).

Entre os estudos já realizados sobre a queimada da cana-de-açúcar, o uso do fogo na agricultura é condenado há mais de um século pelos manuais de conservação do solo e edafologia, pelas conseqüências negativas por ele provocadas na produtividade da terra. No entanto, é milenar a utilização da queimada para a retirada de florestas e campos, visando à implantação de pastagens e lavouras. (FERREIRA, 1991).

Desde a década de 70 as questões ambientais vêem permeando as discussões sobre os grandes problemas da humanidade. No estado de São Paulo, a pressão a respeito do problema da queima de cana-de-açúcar por organizações não-governamentais, ambientalistas, sociedade civil e órgãos ambientais estaduais, fez com que em 19 de setembro de 2002, ocorresse à sanção da lei estadual 11.241 que dispõe sobre a eliminação das queimadas.

No entanto, apenas com o decreto 47.700/2003, ocorreu à regulamentação desta lei. A partir disso, foram implantados os procedimentos e 
critérios necessários à realização da queima da cana-de-açúcar, respeitando as condições de temperatura e umidade relativa do ar da região, no intuito de não ocasionar riscos a população, ou quando a qualidade do ar atingir comprovadamente índices prejudiciais à saúde humana, constatados segundo o fixado em lei. Autorizou-se a queima até o ano de 2031.

O fator físico primário para definir o cronograma de enquadramento das plantações é o tamanho da área de cultivo a ser colhido no ano, acima ou abaixo da referência de área de 150 ha. (cento e cinqüenta hectares). Sobre os terrenos com áreas iguais ou superior a 150 ha. deverá ainda ser verificada a ocorrência de parcelas, com declividade superior a $12 \%$ ou com estruturas de solo que inviabilizem a adoção das técnicas de mecanização.

Conforme cronograma definido no artigo $2^{\circ}$ do Decreto 47.700, de 11 de março de 2003, para as plantações em áreas mecanizáveis, iguais ou superiores a 150 ha o prazo limite para a eliminação da queima da palha é o ano de 2021 . A eliminação da queima da palha nas áreas inferiores a 150 ha e áreas nãomecanizáveis deverá ocorrer entre 2011 e 2031, conforme se observa na

Tabela 2.

Tabela 2. Percentual de redução de queima. Fonte: Secretaria Estadual do Meio Ambiente.

\begin{tabular}{|c|c|c|c|}
\hline ANO & $\begin{array}{l}\text { ÁREA MECANIZÁVEL ONDE NÁO SE } \\
\text { PODE EFETUAR A QUEIMA DA QUEIMA }\end{array}$ & \multicolumn{2}{|c|}{ PERCENTAGEM DE ELIMINAÇÃO } \\
\hline $1^{\circ}$ ano (2002) & $20 \%$ da área cortada & \multicolumn{2}{|c|}{$20 \%$ da queima eliminada } \\
\hline $5^{\circ}$ ano $(2006)$ & $30 \%$ da área cortada & \multicolumn{2}{|c|}{$30 \%$ da queima eliminada } \\
\hline $10^{\circ}$ ano (2011) & $50 \%$ da área cortada & \multicolumn{2}{|c|}{$50 \%$ da queima eliminada } \\
\hline $15^{\circ}$ ano (2016) & $80 \%$ da área cortada & \multicolumn{2}{|c|}{$80 \%$ da queima eliminada } \\
\hline $20^{\circ}$ ano $(2021)$ & $100 \%$ da área cortada & \multicolumn{2}{|c|}{ Eliminação total da queima } \\
\hline ANO & \multicolumn{2}{|c|}{$\begin{array}{l}\text { ÁREA NÁO MECANIZÁVEL, COM PERCENTAGEM DE } \\
\text { ELIMINAÇÂO DECLIVIDADE SUPERIOR A } 12 \% \text { E/OU DA } \\
\text { QUEIMA MENOR DE } 150 \text { ha (cento e cinqüenta hectares) }\end{array}$} & $\begin{array}{l}\text { ONDE NÄO SE PODE } \\
\text { EFETUAR A QUEIMA }\end{array}$ \\
\hline $10^{\circ}$ ano (2011) & \multicolumn{2}{|l|}{$10 \%$ da área cortada } & $10 \%$ da queima eliminada \\
\hline $15^{\circ}$ ano (2016) & \multicolumn{2}{|l|}{$20 \%$ da área cortada } & $20 \%$ da queima eliminada \\
\hline $20^{\circ}$ ano (2021) & \multicolumn{2}{|l|}{$30 \%$ da área cortada } & $30 \%$ da queima eliminada \\
\hline $25^{\circ}$ ano $(2026)$ & \multicolumn{2}{|l|}{$50 \%$ da área cortada } & $50 \%$ da queima eliminada \\
\hline $30^{\circ}$ ano (2031) & \multicolumn{2}{|l|}{$100 \%$ da área cortada } & $100 \%$ da queima eliminada \\
\hline
\end{tabular}

A partir desta Lei os plantadores de cana-de-açúcar, para realizar a queima, precisam comunicar a Secretaria Estadual do Meio Ambiente (SMA).

Segundo a SMA os procedimentos burocráticos para agendamento e controle da queima foram reestruturados apenas em 2005, por isso a própria secretaria tem um déficit de informações dos anos anteriores, mesmo a lei tendo sido sancionada anteriormente.

De acordo com o artigo 10 (Disposições transitórias da lei 11.241/2002) até o dia 31 de dezembro de 2006 os plantadores de cana-de-açúcar que não atingirem o percentual estabelecido de $30 \%$ de redução na queima de área mecanizável, deverão apresentar a SMA no prazo de 90 dias um compromisso de ajustamento de conduta de modo a atender 0 artigo $2^{\circ}$ desta lei, resguardando os impactos sócio-políticos-econômicos e ambientais.

No mês de agosto de 2006, no período de uma semana, ocorreu a suspensão da queima em todo o estado de SÃO PAULO devido à baixa umidade relativa do ar. 
A autoridade ambiental determinará a suspensão da queima quando: Constatado e comprovado risco de vida humana, danos ambientais ou condições meteorológicas desfavoráveis. (Lei Estadual11. 241/02, art.70 parágrafo I)

A lei encontra-se em processo de efetivação prática com algumas propostas cumpridas, mas, em relação aos impactos sobre a população das cidades circundantes, estas ainda sofrem o efeito da poluição do ar e da fuligem. Tal efeito pode ser evidenciado em Ourinhos no período da safra, em que a cidade é tomada pela fumaça negra das queimadas e depósito de fuligem nas casas, evidenciando também o descumprimento desta legislação, a qual menciona que:

O responsável pela queima deverá: realizar a queima preferencialmente no período noturno, compreendido entre o pôr e o nascer do sol, evitando-se os períodos de temperatura mais elevada e respeitando-se as condições dos ventos predominantes no momento da operação de forma a facilitar a dispersão da fumaça e minimizar eventuais incômodos à população. (Lei 11.241/02, art $5^{\circ}$ parágrafo I )

A atuação de uma técnica agrícola rudimentar na produção de uma das principais commodities brasileiras é ainda utilizada, pois favorece uma pequena parcela. Esta parcela é composta por agricultores e usineiros que justificam a queimada como meio de evitar o desemprego dos trabalhadores rurais e assim evitar o impacto social, pois a maioria desses trabalhadores rurais não possui grau de escolaridade pertinente para executar outras atividades, por isso, são fadados ao desemprego estrutural.

No entanto, os impactos ambientais provocados colocam em xeque os argumentos sócio-econômicos a favor desta técnica instaurada desde os primórdios da civilização no período neolítico, sendo fortalecida durante o período de subsídios do pró-álcool e permanece atualmente no nosso meio técnico-científico-informacional. Além disso, a área plantada de cana-de-açúcar no estado de São Paulo vem ultrapassando os limites da região Norte e Nordeste e se expandindo para antigas áreas produtoras de café, soja, milho e pecuária, como na região Sudoeste e no Extremo Oeste Paulista.

Em 2007, foi estabelecido durante o evento Ethanol Summit-São Paulo, um protocolo Agro-Ambiental entre o Governo do Estado de São Paulo e a Única representante do setor sucroalcoleeiro, que teve por objetivo reduzir a queima da palha da cana-de-açúcar em prazo mais curto do que o previsto na lei 11.241/02, respectivamente nos anos de 2014 e 2017, para as áreas consideradas mecanizáveis e não mecanizáveis.

Ressalta-se que nem todos os usineiros e fornecedores do estado de São Paulo aderiram ao protocolo agroambiental, e como este ainda não se tornou decreto o que judicialmente continua em vigor para limitar a prática de queima da cana-de-açúcar é a lei 11.241/2002.

No intuito de verificar a quantidade de hectares queimados na cidade de Ourinhos foram coletados os dados da Secretaria Estadual do Meio Ambiente para os anos de 2005 e 2006. No entanto, observou-se que o procedimento de coleta do plano de queimadas estipulado pelos agricultores e usineiros a esta entidade pública, é realizado em uma escala espacial que ultrapassa os limites municipais e se estendem pela região de Governo de Ourinhos. Evidencia-se a importância do estudo da região para saber a influência no local, pois, as correntes de vento levam esses poluentes da área produtora até as cidades mais próximas. 
De acordo com a Secretaria Estadual do Meio Ambiente a região de governo de Ourinhos é composta pelos municípios de Ourinhos, Salto Grande, São Pedro do Turvo, Espírito Santo do turvo, Santa Cruz do Rio Pardo, Canitar Chavantes, Ipaussu, Timburi, Bernardino de Campos, Ribeirão do Sul e Óleo.

Os dados mensais de hectares queimados coletados e tabulados, fornecidos por esta secretaria demonstram que o município com maior quantidade de hectares queimados em 2005/2006 foi Santa Cruz do Rio Pardo (15.881 ha.), seguido de Ipaussu (12.041ha.) e Ourinhos (11.954 ha.)

A partir do recorte da imagem de satélite (Figura 2), a composição colorida permitiu identificar algumas das muitas áreas escuras identificadas como área de queimada, devido à baixa refletância nesta faixa espectral. A presença de cicatrizes de queimadas na região de Ourinhos é notória, o que tornou importante para essa pesquisa diagnosticar a quantidade de hectares queimados mensais para uma análise conjunta das condições meteorológicas capazes de levar através das correntes de vento os gases e particulados, às cidades mais próximas.

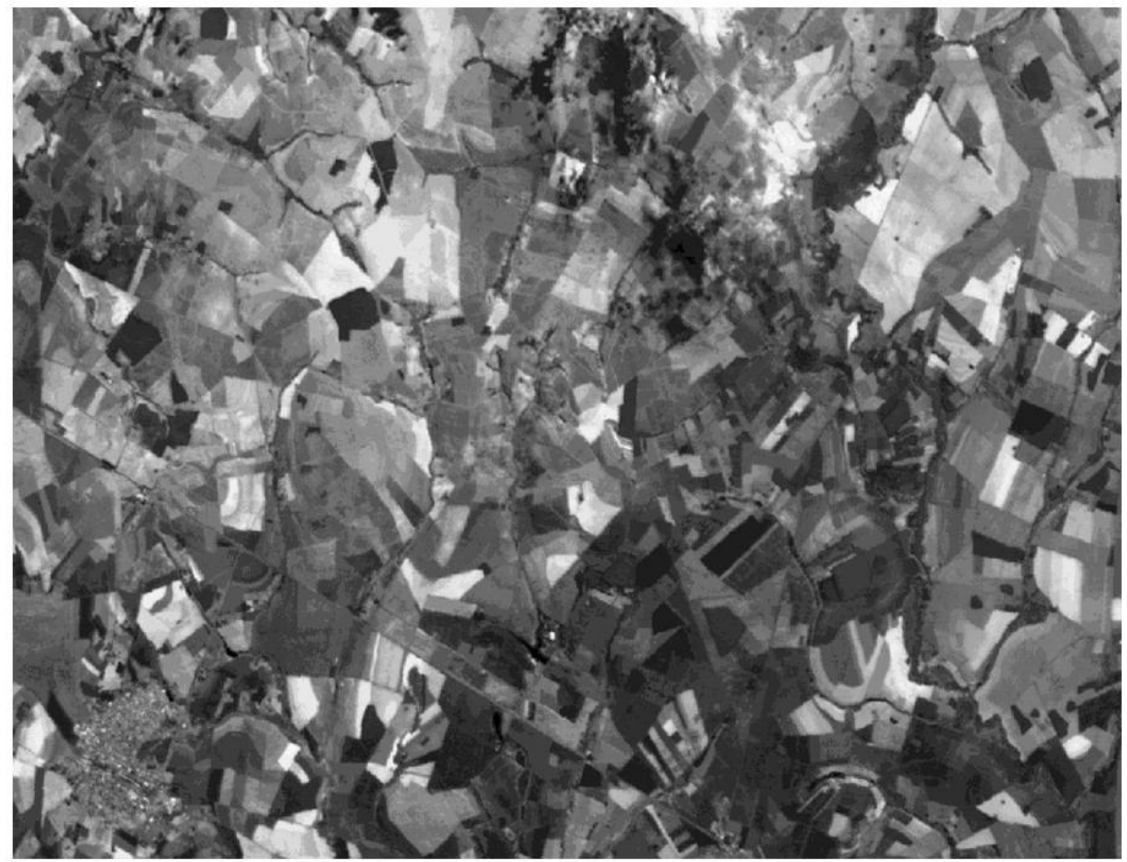

Figura 2. Recorte da imagem sintética CBERS na Região de Ourinhos. Órbita / Ponto: 157/126. Composição colorida R4 B2 G3, data 6-9-2006.

Organização: ALEIXO (2008).

A partir dos dados mensais da quantidade de hectares queimados, no Gráfico 1, observou-se que o aumento dos totais mensais ocorre em maio e segue com pequenos rebaixamentos até julho e elevações em agosto. No ano de 2005, os meses de maio e agosto apresentaram os maiores totais de hectares queimados e, no ano de 2006 , os meses de junho e agosto. 
Gráfico 1. Quantidade de hectares mensais queimados na Região de Governo de Ourinhos

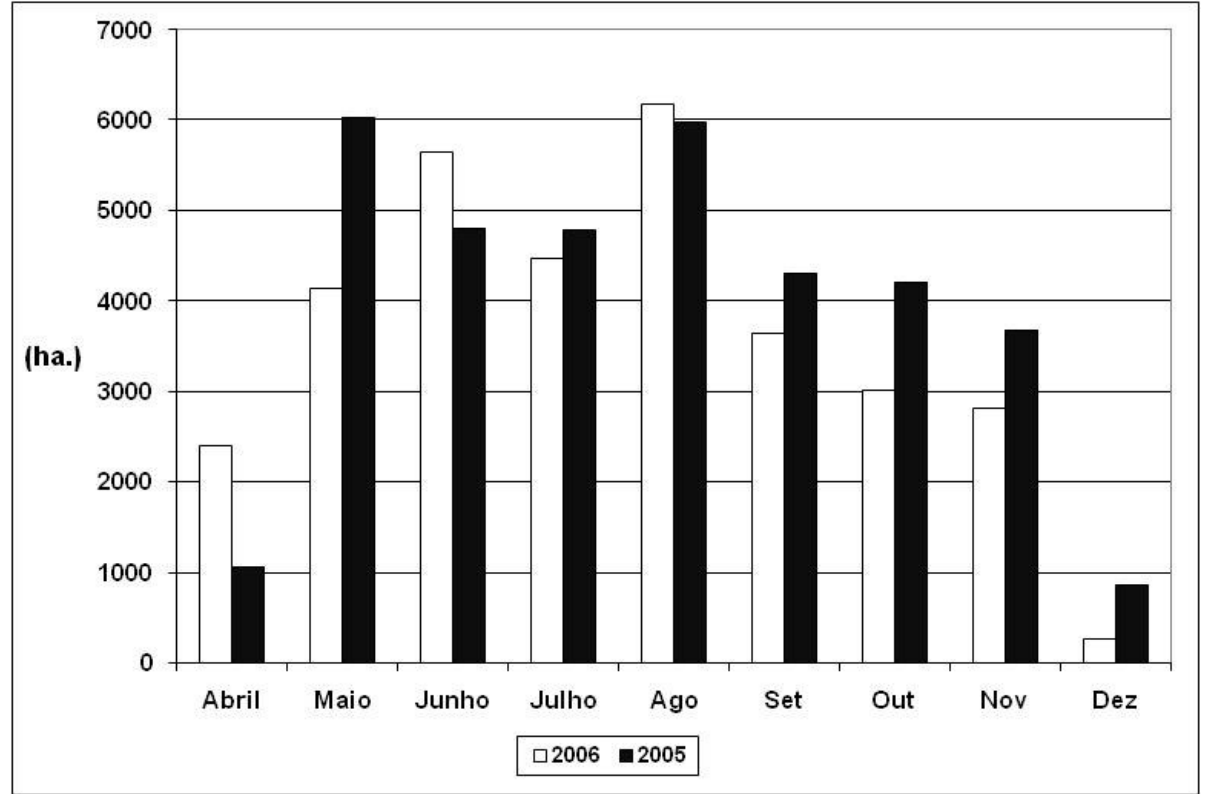

Fonte: Secretaria do Meio Ambiente. Organização: ALEIXO (2008).

Assim o mês de agosto, devido à estação de inverno com precipitação pluvial escassa aliada a uma enorme quantidade de poluentes liberados pela queima da cana-de-açúcar pode contribuir potencialmente no aumento e agravo de patologias do aparelho respiratório.

\section{Análise Episódica}

Foram diagnosticados os episódios agudos de poluição do ar conforme a resolução CONAMA 03/90, do período de abril a dezembro de 2005. Com exceção do mês de novembro, que obteve três estados de atenção, todos os demais meses, apresentaram durante a rodagem do modelo CATT-BRAMS, estados de atenção, alerta e emergência na variável monóxido de carbono (CO). O material particulado 2.5, não foi classificado como concentração aguda, mas atingiu nos meses de julho, agosto, setembro e outubro o padrão secundário de $60 \mathrm{ug} / \mathrm{m} 3$.

[...] sinais, cada vez mais evidentes, mostram ser os padrões de qualidade do ar inadequados para a proteção da população mais susceptível à poluição atmosférica. Vários estudos demonstraram ocorrência de efeitos mórbidos em concentrações abaixo dos padrões de qualidade do ar (SALDIVA, 2007, p. 14).

A análise dos dados de inalações demonstra que a alta incidência de casos ocorreu entre os meses de agosto e novembro, particularmente nos meses de setembro e outubro, normalmente quando se inicia o período chuvoso. Ressalta-se que a precipitação é importante para o bem-estar fisiológico do aparelho respiratório, pois é quando ocorre à dispersão dos poluentes com o aumento da umidade. Entretanto, o comportamento dos 
elementos climáticos nos meses anteriores apresentou um evidente período de seca durante os anos analisados, resultando em altas amplitudes térmicas e quedas de temperatura devido à atuação dos sistemas polares (MPA) de trajetória continental com ondas rigorosas de aquecimento pré-frontal e atuação dos sistemas tropicais (MTA).

A distribuição dos elementos climáticos na região de Governo de Ourinhos evidencia semanas de estiagem prolongadas dentre os meses de inverno, coincidindo com os meses com maior número de hectares queimados e episódios de estados de atenção, alerta e emergência de concentração de monóxido de carbono e material particulado segundo os padrões de qualidade do ar da resolução Conama 03/90.

Pode-se observar que a precipitação pluvial correlacionou-se fortemente ao processo de queima da cana-de-açúcar, ou seja, o período chuvoso apresentou uma relação inversamente proporcional à quantidade de hectares queimados.

Gráfico 2. Relação entre Hectares queimados e Precipitação Pluvial.

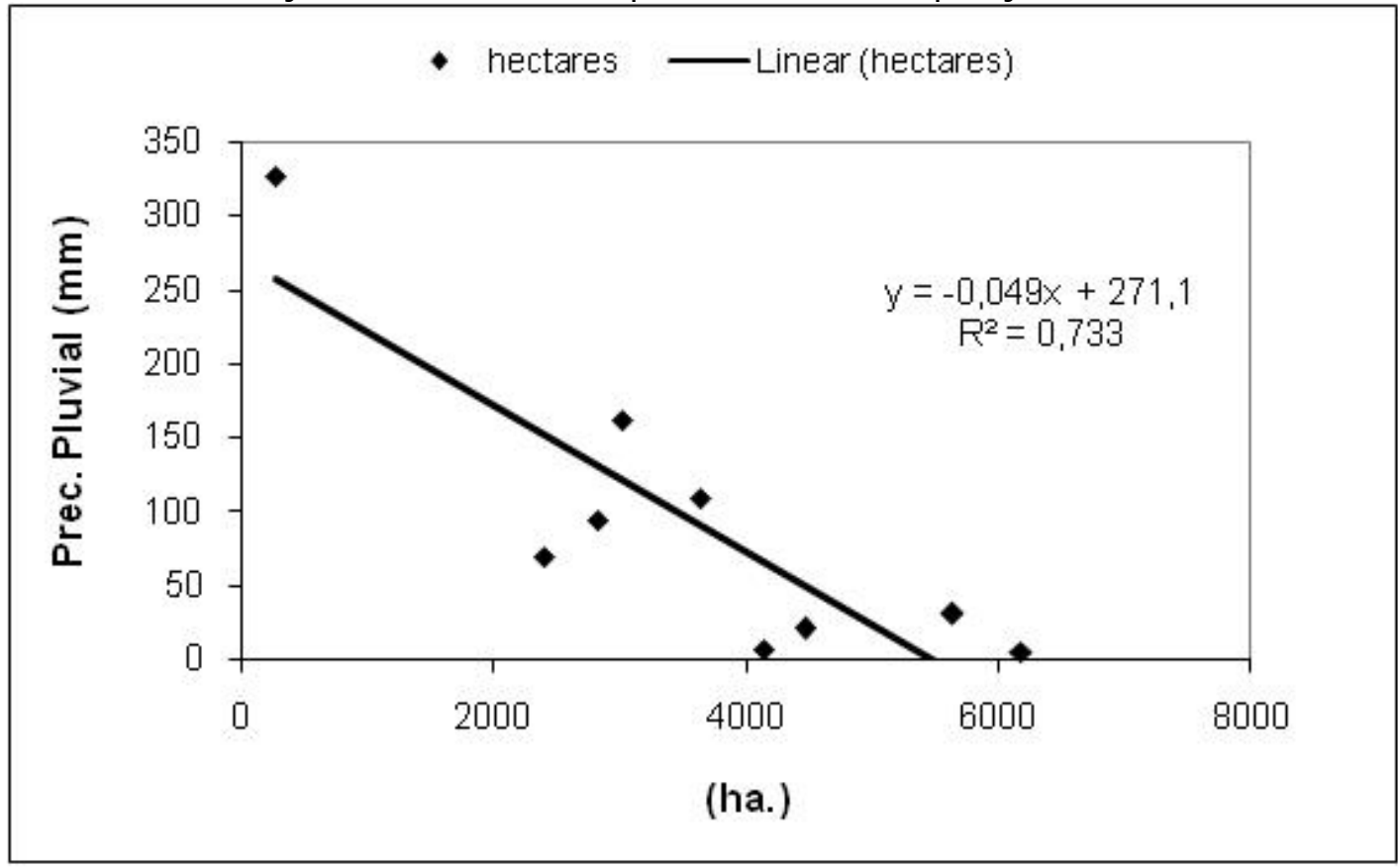

Fonte: IAC e SMA. Organização: ALEIXO (2007)

De acordo com o Gráfico 3 e a Figura 3, observa-se que o ocorre um aumento do total de atendimentos por inalações três dias após as altas concentrações de CO (500 ppb) e M.P 2.5 (55 ug/m3) na atmosfera local, ressalta-se na Figura 3 o contorno do município de Ourinhos atingindo concentrações de CO consideradas pela Companhia de tecnologia e Saneamento Ambiental do estado de São Paulo (CETESB), como um episódio agudo de poluição do ar. Cabe lembrar que o período de 20 a 27 de agosto de 2005, apresentou baixa quantidade de precipitação pluvial e queda da temperatura mínima a partir do dia 25/08. Essas condições meteorológicas, aliadas ao aumento de poluentes decorrente da combustão da biomassa, propiciaram no dia 28/08 a procura da população pelo serviço de inalação. 
Gráfico 3. Elementos climáticos e inalações no período de 20/8/2005 a 31/08/2005.

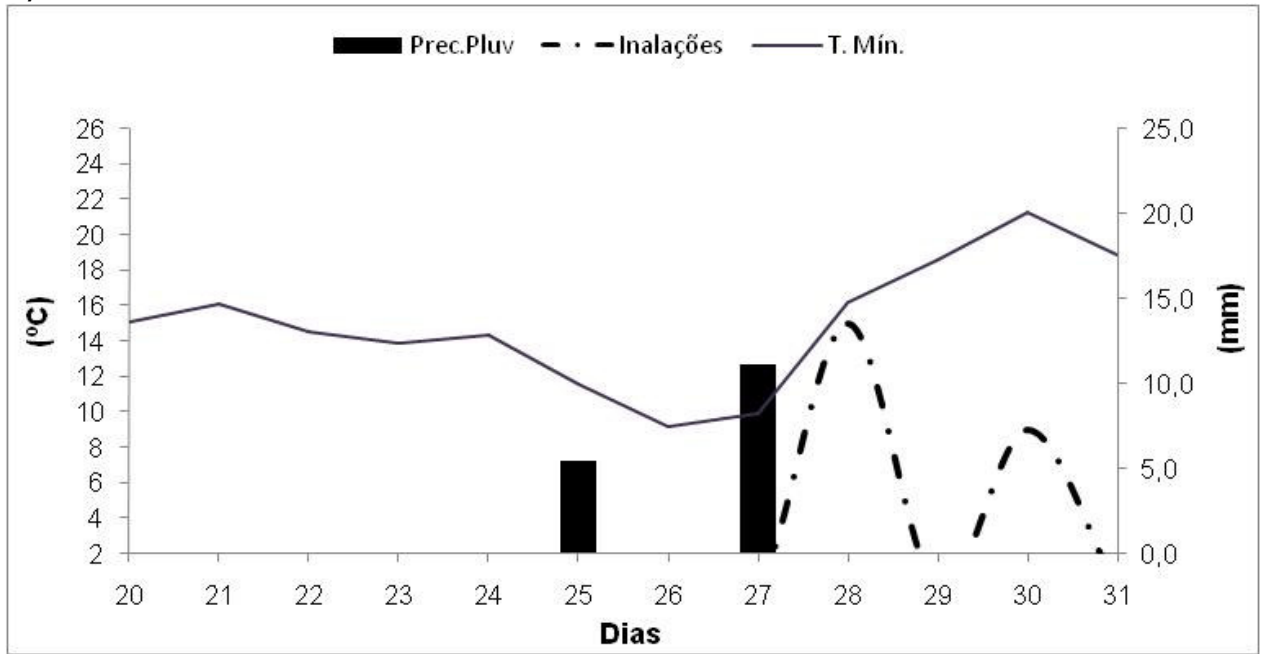

Fonte: IAC e Unimed Ourinhos. Org.: ALEIXO (2007).

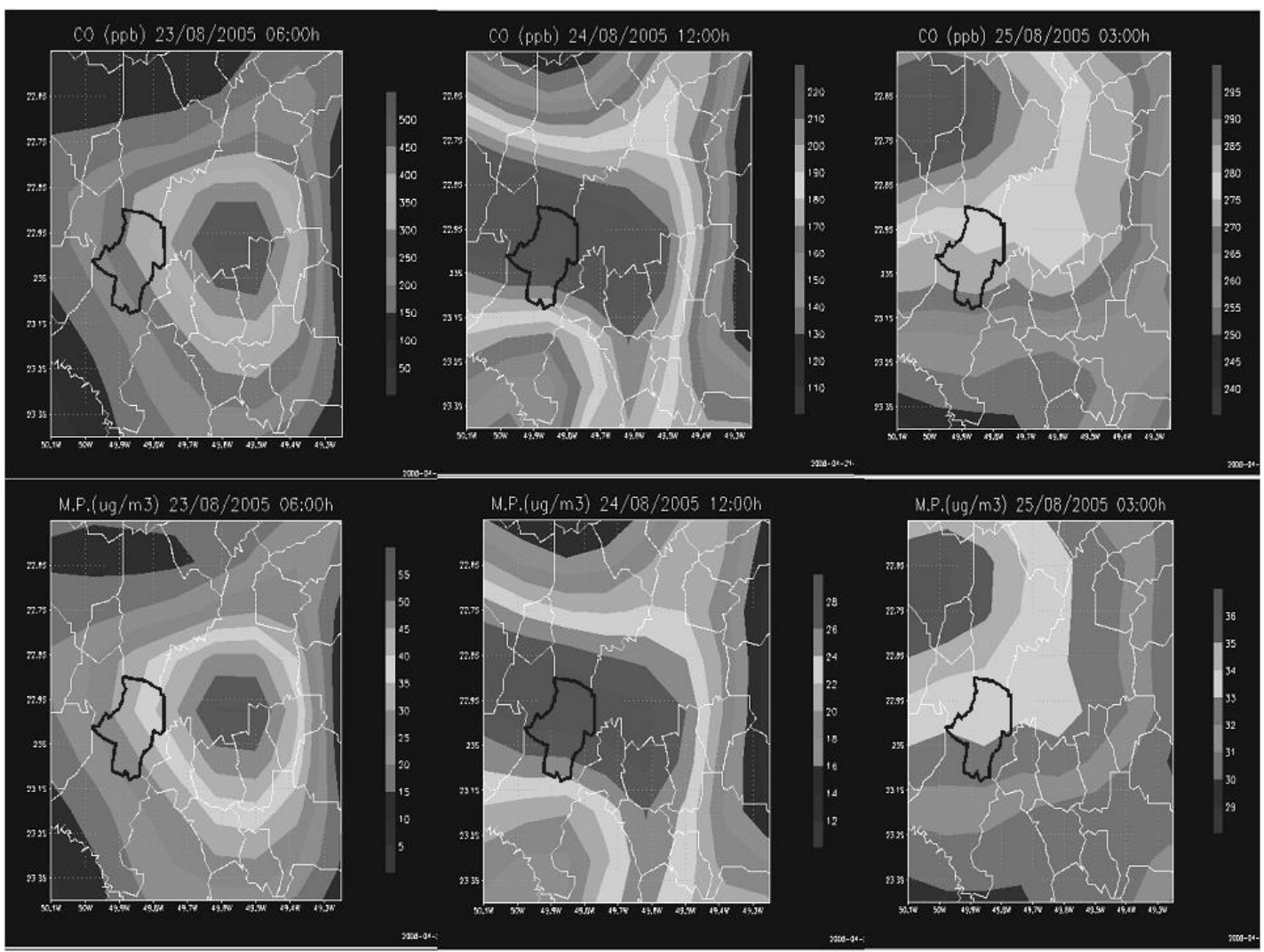

Figura 3. Episódios de atenção e emergência de $\mathrm{CO}$ e concentração de material particulado 2.5 dos dias 23, 24 e 25/08/2005.

Organização: ALEIXO (2008). 
A imprensa local associou o aumento de doenças respiratórias com o período seco e os resíduos de queimadas de acordo com a Figura 4.

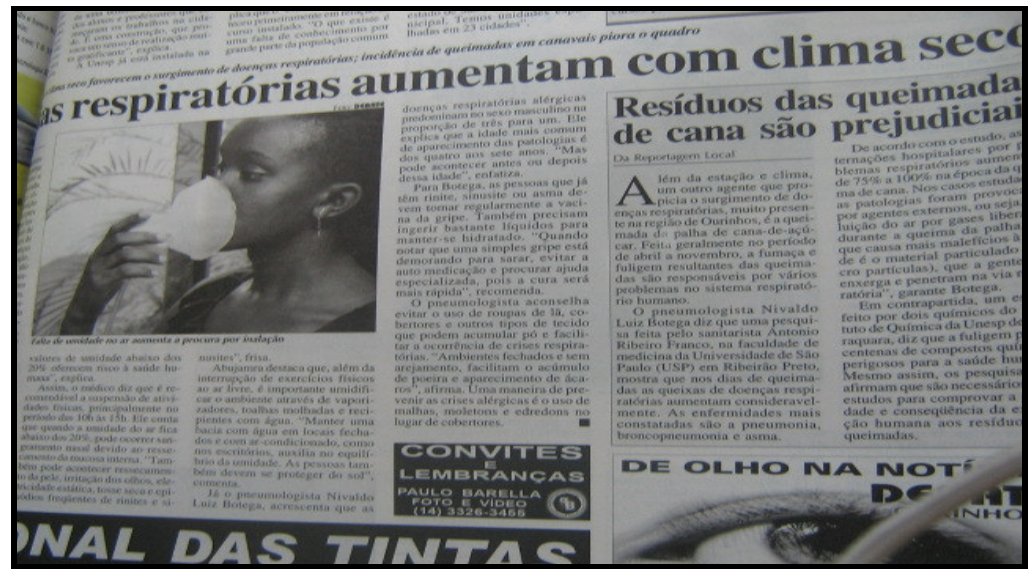

Figura 4. Notícia veiculada no jornal local Debate dia 21/08/2005.

O gráfico 4 demonstra que após um período de umidade relativa muito baixa, iniciando-se sempre a partir das 16:00h. até ás 23:00h., quando volta a subir, os valores mínimos chegam a valores bem inferiores a $20 \%$ (medida crítica de umidade relativa, segundo a OMS).

Gráfico 4. Elementos climáticos e inalações do período de 10/8/2006 a $10 / 9 / 2006$

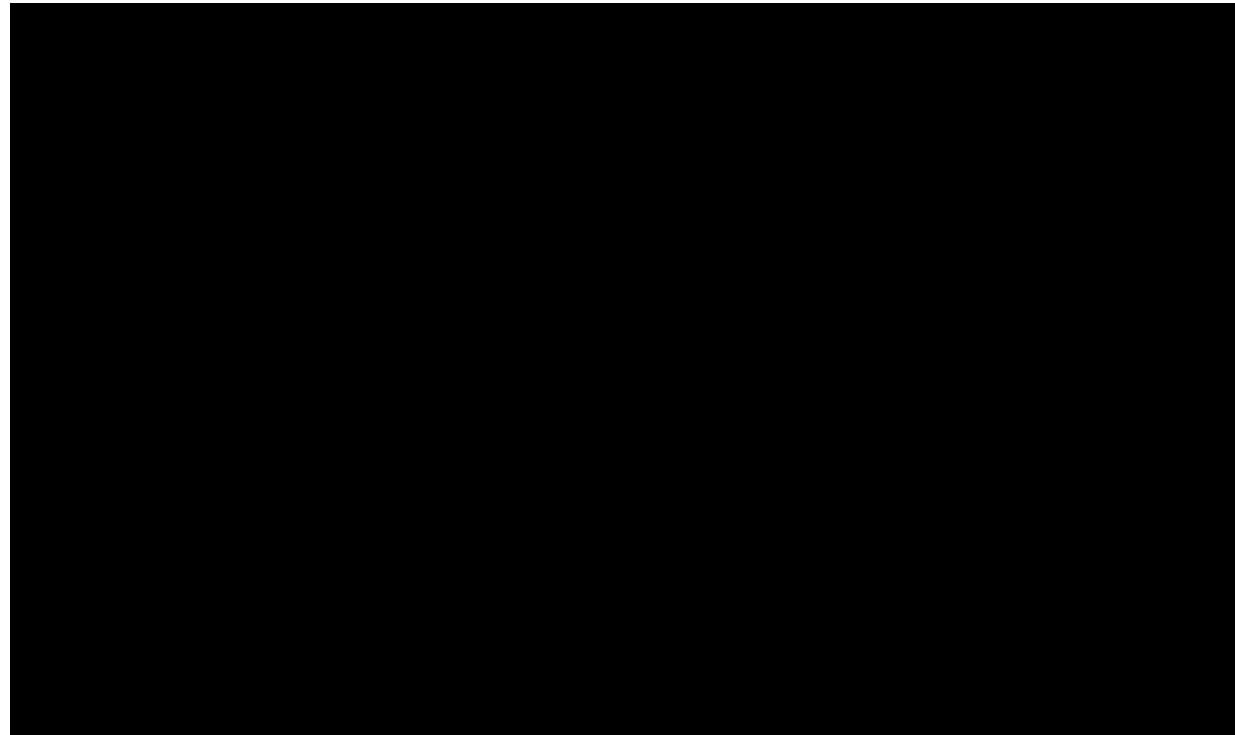

Fonte: Plataforma Meteorológica Unesp/Ourinhos e Unimed Ourinhos. Organização: ALEIXO (2007).

Com isso, após um período de 11 dias de valores baixos de umidade relativa o aumento de inalações é contínuo. Neste episódio os jornais retrataram a problemática da queima da cana-de-açúcar atingindo cidade de Ourinhos, deixando a cidade imunda. Cabe lembrar que o mês de agosto apresentou o maior número de hectares queimados (6.179 ha). 
Nas escolas, $86,25 \%$ (gráfico 5), dos alunos entrevistados (160 no total) já contraíram alguma patologia respiratória, principalmente bronquite, cuja ocorrência de acordo com a bibliografia especializada é relacionada principalmente a poluição do ar. Logo em seguida têm-se a ocorrência de sinusite e pneumonia.

Os sintomas prevalentes nas crianças de 9 anos indicaram uma forte relação das doenças brônquicas e, as que são prevalentes também das variações dos tipos de tempo como a sinusite.

Gráfico 5. Patologias respiratórias contraídas pelos alunos entrevistados

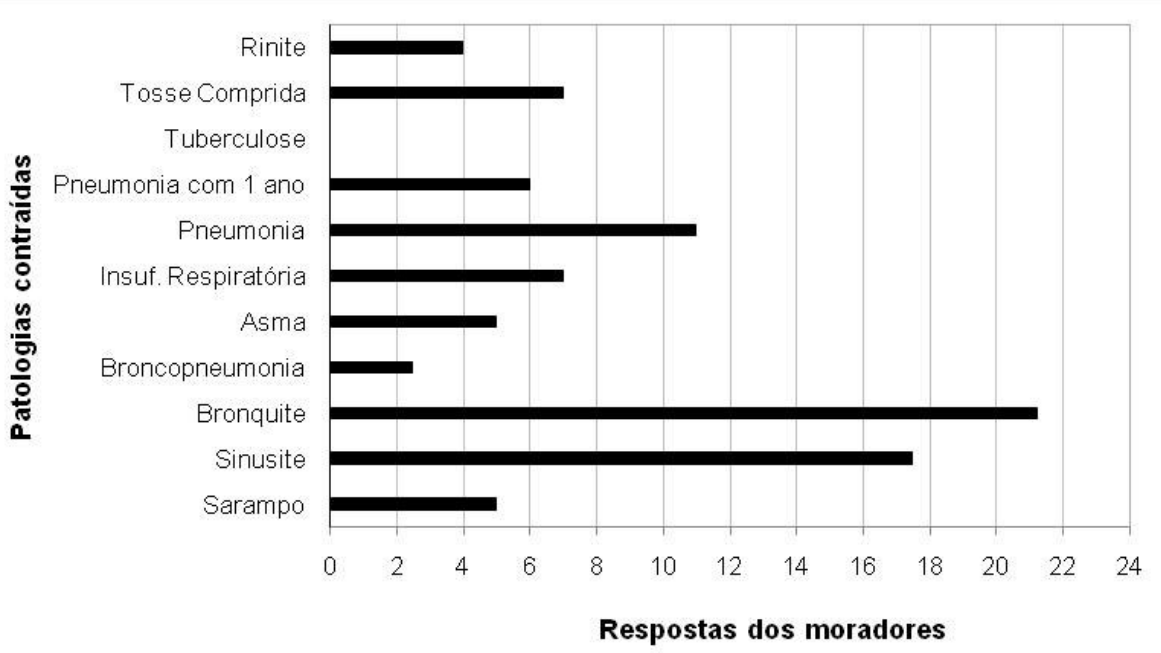

Organização: ALEIXO, (2008).

Do total de moradores com incidência de doenças respiratórias em suas residências, a maior parte declarou que os primeiros sintomas ocorrem no período de inverno, durante a noite. Os entrevistados afirmaram procurar o serviço de saúde público freqüentemente e consideraram como bom 0 atendimento.

Gráfico 6. Principais fontes de poluição da cidade de Ourinhos.

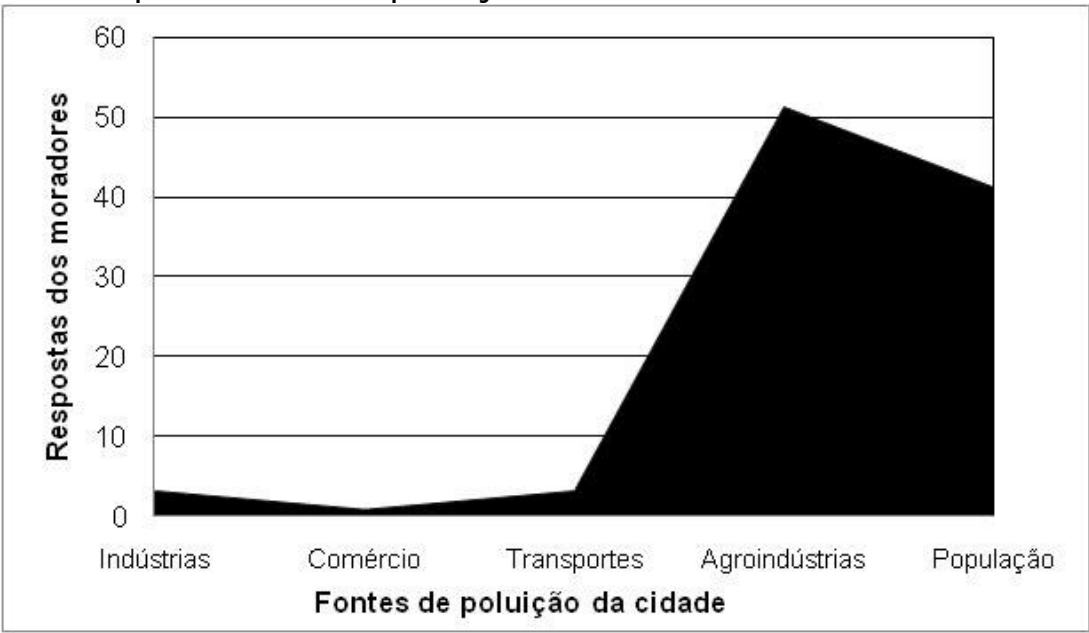


Entretanto, a maioria dos moradores percebeu que os períodos de estiagem aliados à queima da cana-de-açúcar são potencialmente agravantes ao aparelho respiratórios. Por isso, os entrevistados definiram a atividade sucroalcoleeira como principal agente de poluição na cidade.

\section{CONSIDERAÇÕES FINAIS}

A partir da pesquisa efetuada, compreendeu-se as diferentes relações envolvidas no processo de saúde e doença, e como as patologias respiratórias se evidenciam na cidade em áreas particularmente mais expostas aos produtos da queima da cana-de-açúcar.

Com a diminuição da umidade relativa a valores horários críticos abaixo de $20 \%$ os episódios puderam ser evidenciados principalmente nos meses de julho e agosto de 2005 e 2006. Isso se relaciona com o aumento de inalações a partir de maio e principalmente nos meses com maior escassez de chuva (junho, julho e agosto) e de internações nos dois meses subseqüentes, setembro e outubro, ou seja, o agravo das patologias ocorre logo depois de um período de tipos de tempo com escassez de chuva, temperatura mínima com valores baixos e valores críticos de umidade relativa.

Verificou-se que os gases e partículas liberadas durante a queima da cana-de-açúcar são potencialmente agravantes ao aparelho respiratório. Através dos episódios diagnosticados observa-se a intrínseca relação entre estados agravantes da atmosfera, a ocorrência de episódios agudos de poluição do ar e o aumento na incidência de atendimentos por inalações na cidade de Ourinhos.

Principalmente durante o período de inverno, as condições meteorológicas apresentaram situações propícias aos agravos do aparelho respiratório. Com a velocidade do vento de pequena intensidade, que não possibilita a dispersão dos gases e poluentes lançados na atmosfera pela queima da cana-de-açúcar. Além disso, observa-se que a concentração de monóxido de carbono e material particulado 2.5 aumenta continuamente até o mês de agosto quando atinge o valor mais alto, coincidindo com o valor estabelecido pela CETESB como concentração máxima permitida, a qual não deve ser ultrapassada mais de uma vez ao ano.

As correlações efetuadas demonstram em alguns meses o efeito da temperatura mínima e da escassez de chuva no aumento de atendimento por inalações na cidade, bem como, a forte relação do total de hectares queimados com a falta de precipitação pluvial.

O noticiário do jornal local bem como os questionários aplicados nas quatro áreas da cidade, comprovam que é no inverno, no período noturno, e com a alta quantidade de hectares queimados, que a atmosfera urbana torna-se um lócus potencialmente pernicioso para as pessoas predispostas às morbidades do aparelho respiratório.

A queima da cana-de-açúcar atinge toda a população, por isso, é o principal problema ambiental e fonte de poluição mencionada pelos moradores destas áreas, que também sofrem com a vulnerabilidade social decorrente da materialização da desigualdade de classes do modo de produção no espaço urbano. 


\section{REFERÊNCIAS}

CETESB. Qualidade do ar: Padrões da resolução Conama 03/90. Disponível em: http://www.cetesb.sp.gov.br. Acesso: agosto de 2007.

DATASUS. Banco de dados do sistema único de saúde. Disponível em: www.datasus.gov.br. Acesso em: outubro de 2006 e novembro de 2007.

FERREIRA, M.E.T. (1991). Aspectos Agronômicos da Queimada da Canade-açúcar. Palestra ministrada aos 22 de outubro de 1991. Reunião do Centro de Estudos Regionais. Universidade de São Paulo. Ribeirão Preto. SP.

FREITAS, S.; LONGO, K.et al. Emissões de queimadas em ecossistemas da América do Sul. Estudos avançados vol.19, n53, São Paulo, 2005.

FREITAS, S.; LONGO,K.et al. Assimilação de aerossóis atmosféricos por satélite no modelo de transporte químico CATT - BRAMS. Anais XIII Simpósio Brasileiro de Sensoriamento Remoto, Florianópolis, Brasil, 21-26 abril 2007, INPE, p. 4473-4475.

IBGE. Instituto Brasileiro de Geografia e Estatística. Disponível em: www.Ibge.gov.br/cidades. Acesso em: maio de 2006 e agosto de 2007.

MONTEIRO, C.A. de F. A dinâmica climática e as chuvas no estado de São Paulo: Estudo geográfico sob a forma de Atlas. USP/Igeog. São Paulo, 1973.

SECRETARIA DO MEIO AMBIENTE. Lei Estadual 11.241/02. Disponível em: http://sigam.ambiente.sp.gov.br/sigam2. Acesso: maio de 2007.

SALDIVA, P.H. Vigilância dos efeitos na saúde decorrentes da poluição atmosférica: um estudo de factibilidade. Cepis,OMS, 2007. Disponível em: www.cepis.ops-oms.org.br/brasil. Consultado em: outubro de 2007.

SANT'ANNA NETO, J.L; ZAVATINI, J.A (org). Variabilidade e Mudanças climáticas: Implicações ambientais e socioeconômicas. Maringá: Eduem, 2000.

União da Agroindústria canavieira. Informações estatísticas. Disponível em: www.unica.com.br. Consultado em abril de 2008. 